EESTI NSV TEADUSTE AKADEEMIA TOIMETISED. XVI KOIDE KEEMIA * GEOLOOGIA. 1967, NR. 1

ИЗВЕСТИЯ АКАДЕМИИ НАУК ЭСТОНСКОН ССР. ТОМ ХVI ХИМИЯ * ГЕОЛОГИЯ. 1967, Nㅗ 1

\title{
О ВОЗРАСТЕ НИЖНИХ ГОРИЗОНТОВ СИЛУРА ЭСТОНИИ
}

И. Чиер (Kiaer, 1908) в своем прекрасном труде о силуре района Осло пришел к выводу об отсутствии в Эстонии нижнего лландовери. C тех пор вопрос о перерыве на границе ордовика и силура в Прибалтике, связанный прежде всего с корреляцией лландоверийских отложений, затрагивался многими авторами.

Сам И. Чиер, называя ряд общих для лландовери Норвегии и Эстонии видов брахиопод и трилобитов (в частности, Pentamerus borealis Eichw., распространенный в слоях $6 c \beta$ и 7 а Норвегии и $\mathrm{G}_{2}$ Эстонии), сопоставляет юуруские $\left(\mathrm{G}_{1}\right)$ и тамсалуские $\left(\mathrm{G}_{2}\right)$ слои со слоями 7 a. Поскольку поркуниский горизонт $\left(\mathrm{F}_{2}\right)$, по его мнению, соответствует слоям $5 \mathrm{~b}$, то, следовательно, в Эстонии отсутствуют аналоги слоев 6 Норвегии и верхнелландоверийские (Чиер пользуется двухчленным делением лландовери) отложения лежат на ордовике «дискордантно».

В. Твенхофель (Twenhofel, 1916), сопоставляя $\mathrm{G}_{1-2}$ c формацией ГанРивер, не находит в Эстонии эквивалента формации Бекси-Ривер нижнего лландовери.

K. Тейхерт (Teichert, 1928), учитывая, что ни в одном из рассмотренных им регионов (Англия, Скандинавия, о. Антикости, штат Нью-Иорк) пентамерусы из групп $P$. borealis и $P$. oblongus в низах лландовери не встречаются, относит $\mathrm{G}_{2}$ к среднему лландовери, а $\mathrm{G}_{1}-\mathrm{k}$ верхам нижпего или к началу среднего лландовери.

Э. Розенштейн (Rosenstein, 1940) на основе находок Stricklandia aff. lens Sow. из юуруских слоев показала, что $\mathrm{G}_{1}$ следует сопоставлять со слоями $6 \mathrm{c}$ (и, вероятно, 6b Норвегии), заполняя тем самым в некоторой степени перерыв на границе ордовика и силура в Эстонии, существование которого предполагалось предыдущими авторами.

Ю. Мартна (Martna, 1957) пошел еще дальше и поставил существование перерыва вообще под сомнение. Он утверждал, что ярус 6 является единой биостратиграфической единицей и его подразделение является по существу литостратиграфическим, не имеющим серьезного корреляционного значения. Следовательно, по Ю. Мартна, ярус 6 Норвегии, возможно, целиком соответствует юуруским слоям Эстонии.

А. Аалоэ (1958) отрицает существование перерыва между поркуниским и юуруским горизонтами: он сопоставляет $\mathrm{G}_{2}$ с $7 \mathrm{a}, \mathrm{G}_{1}$ с $6 \mathrm{c}+6 \mathrm{~b}$, a 6 а с так наз. койгискими слоями, которые разные авторы относят либо к поркунискому горизонту (Аалоэ, 1958), либо к юуруским слоям (Мян- 
ғиль, $1949 *)$. К сожалению, приведенная корреляция недостаточно аргументирована.

В последние годы в связи с переводом поркуниского горизонта в ордовик в корреляционных схемах снова стали показывать перерыв на границе ордовика и силура, а юуруские и тамсалуские слои совместно с райккюласким горизонтом стали сопоставляться со средним лландовери других стран (Никифорова, Обут, 1965 и др.). Поскольку с названными слоями связан известный и широко распространенный фаунистический комплекс с Palaeofavosites paulus Sok., P. balticus (Rukh.), Zygospiraella duboisi (Vern.), Pentamerus borealis (Eichw.) и др., то правильная возрастная интерпретация соответствующих слоев имеет существенное значение.

Хотя накопившаяся у нас к настоящему времени коллекция граптолитов и невелика, она все же позволяет обсудить затронутые выше вопросы на новом уровне. Часть нового фактического материала предоставлена нам геологами Управления геологии СМ ЭССР К. Каяком и Э. Кала, за что автор им глубоко благодарен.

В этой коллекции, хранящейся в Геологическом музее АН ЭССР, имеются следующие 12 видов граптолитов (без учета дендроидей и многих экземпляров, определенных до рода) из юуруских и тамсалуских слоев и райккюлаского горизонта.

\section{Climacograptus scalaris cf. ferganensis Obut}

М а тери ал: скв. Канакюла, гл. 125,3 м; скв. Кирикукюла, гл. 84,4 м; скв. Курси, гл. 46,8 м; скв. Отепя, гл. 332,3 и 332,6 м.

3 амеч ания. Несомненно, представитель группы scalaris, но отличается от других подвидов некоторыми деталями строения. Ближе остальных стоят $\mathrm{Cl}$. scalaris transgrediens Waern и $\mathrm{Cl}$. s. ferganensis Obut. От первого наша форма отличается более сильным проксимальным концом $(0,8-0,9$ м.м против $0,6-0,75$ на уровне первой теки) и более густо расположенными теками - на 10 мм приходится $14-11$ тек (обычно 13-12); интервал между устьями первой $\left(\mathrm{t}_{1}\right)$ и пятой $\left(\mathrm{t}_{5}\right)$ тек $2,7-2,8$ м. против 2,8-3,4 м.м у transgrediens. От среднеазиатской формы почти не отличается, но для точной идентификации данных слишком мало. Близок также $\mathrm{Cl}$. medius, но он крупнее, имеет хорошо развитую длинную виргеллу и септа у него начинается позже.

Длина рабдосом наших экземпляров доходит до $1,5 \mathrm{cM}$, ширина на уровне устья $\mathrm{t}_{1}-0,8-0,9$, у $\mathrm{t}_{3}-1,1-1,25$, в дистальной части - $1,5-1,6$ мм; виргелла очень короткая $\left(0,1-0,4\right.$ мм), виргула до 2 мм; экскавации охватывают $\frac{1}{5}-\frac{1}{4}$ ширнны рабдосомы.

\section{Climacograptus hughesi (Nicholson)}

М атери ал: скв. Аукси, гл. 119,7 м; скв. Сурвакюла, гл. 189,3 м.

3 а мечания. Признаки эстонских представителей вида хорошо совпадают с таковыми в первичном диагнозе $\mathrm{Cl}$. hughesi. Основные данные следующие: длина неполной рабдосомы $0,75+c M$, ширина на уровне устья $t_{1}-0,7 ; t_{3}-0,85$, в дистальной части - 1,1 м.. На 10 мм приходится 14 тек; интервал между устьями $t_{\text {! }}$ и $t_{5}-2,6$ мм; глубина экскавации $-\frac{1}{3}$ ширины рабдосомы; устья в проксимальпой части почти горизонтальные, в дистальной слегка наклонные; септа в нижней части волнистая, виргелла короткая $(0,25$ м. $)$.

\section{Paraclimacograptus innotatus (Nicholson)}

М а те р и ал: скв. Ванаыуэ, гл. 20,1 ж; скв. Выхма, гл. 104,3 м; скв. Кариярве, гл. 202,7 м; скв. Сурвакюла, гл. 67,4 и 68,0 м.

* Р. Мянниль, Обзор стратиграфии силурийских отложений по линий разреза Таллин-Ярваканди-Выхма (ЭССР), Рукопись, Институт геологии АН ЭССР, Таллин, 1949 
3 а меч ания. Наши экземпляры в общем хорошо соответствуют типичным піредставителям вида. Длина рабдосомы довольно постоянная и равна $0,55-0,68$ мм (только экземпляр из Ванаыуэ достигает длины 1 см). Ширина рабдосомы возрастает довольно быстро: $\mathrm{y}_{1}-0,8-0,95 \mathrm{M.}$, у $\mathrm{t}_{3}-1,05-1,15$ м.м и в дистальной части - 1,2-1,3 мм. Проксимальный конец рабдосомы округленный, и поэтому общий облик ее короткий и толстый. Қак видно, наши экземпляры несколько у́же типичных. На 10 мм приходится 14-13 тек. На некоторых теках сохранились небольшие шипики.

\section{Paraclimacograptus estonus (Schmidt)}

Матери ал: несколько экземпляров из обн. Матсукюла, из нижней чаети райккюлаского горизонта.

3 амечания. Признаки наших экземпляров точно совпадают с признаками, ириведенными в описании вида А. М. Обутом (1960). Наш материал по $P$. innotatus и $P$. estonus показывает, что нх различия весьма постоянны и поэтому, несмотря на большое их сходство между собой, они все же четко различаются.

\section{Paraclimacograptus aff. estonus (Schmidt)}

М а те р и ал: скв. Тори, гл. 82,2 м.

3 а меч ания. Данный экземпляр относится, вероятно, к новому виду, который отличается длинной узкой рабдосомой. Длина рельефной рабдосомы 1,7 см; ширина ее увеличивается медленно: у $\mathrm{t}_{1}$ она равна $0,7 \mathrm{\mu s}$, а максимальная у $\mathrm{t}_{7}-1,05 \mathrm{M \mu}$ (возможна слабая деформация рабдосомы). На 10 мм приходится 14-12 тек. Интервал между устьями $t_{1}$ и $t_{5}-2,5$ мм; устья горизонтальные; на вентральной стороне тек небольшие шипы. Септа начинается ниже устья $t_{2}$; она слабо волнистая. Длина виргеллы 0,5 , виргулы $-2,8+$ мм. Глубина экскаваций $-\frac{1}{4}-\frac{1}{3}$ ширины рабдосомы.

От $P$. estonus данная форма отличается меньшей шириной рабдосомы и более часто расположенными теками. Облик рабдосомы более стройный. Близок также P. sinitzini Chal. из зон Akidograptus acuminatus и Orthograptus vesiculosus ТяньШаня (Халецкая, 1962). Наша форма чуть длиннее, уже и имеет меньше тек ша $10 \mathrm{MM}$.

\section{Diplograptus cf. modestus diminutus Elles \& Wood}

М атери ал: скв. Қирикукюла, гл. 75,1 м.

3 амечания. Наш материал недостаточно полный для точного определения. Хотя основные данные совпадают с данными в диагнозе разновидности, но плохо прослеживается характер тек, типичный для группы modestus.

\section{Orthograptus cf. mutabilis Elles \& Wood}

М а тери ал: скв. Отепя, гл. 329,6 м.

3 а меч ания. Материал недостаточен для точного определения.

\section{Orthograptus bellulus Törn.}

М а те р и ал: скв. Сурвакюла, гл. 66,8 м.

3 амеч ания. Сохранность экземпляра не очень хорошая, но основные приआаки достаточно видны - ширина рабдосомы доходит до 2,3 мм, на 10 мм приходится 13-12 тек, септа отсутствует, виргелла очень длинная - $12+$ м..

9. Rhaphidograptus törnquisti (Elles \& Wood)

М а те р и ал: скв. Охесааре, гл. 408,8 и 409,7 $м$; скв. Отепя, гл. 329,6 ; скв. Ліаэва, гл. $63,7 м$ (сf.).

3 амеч ания. Признаки нашего материала хорошо совпадают с первичным огисанием. Этот вид - один из наиболее распространенных граптолитов в карбонатных отложениях нижнего-среднего лландовери Прибалтики, притом он легко определяется.

10. Pristiograptus atavus (Jones)

М атери ал: скв. Кирикукюла, гл. 73,1 (сf.) и 79,4 ж; скв. Пярну, гл. 189,5 скв. Отепя, гл. 329,6 м; скв. Охесааре, гл, 387,5 м; скв. Сурвакюла, гл. 149,4 и (сf.). 
3 а мечания. Наш материал сохранился сравнительно плохо, в связи с чем правильность определения вызывает некоторые сомнения. В основном характер остатков все же достаточно определенно входит в рамки диагноза вида. Следует отметить, что ширина изученных рабдосом не достигает максимума, а доходит обычно до 1,0 , редко до 1,1 мм; число тек на 10 мм также чаще всего 8-9, в двух случаях всего 7- $7^{1} I_{2}$. Более полно сохранившиеся экземпляры слабо дорсально изогнуты.

11. Pristiograptus cf. sandersoni (Lapworth)

М а тери ал: скв. Кирикукюла, гл. 75,1 м.

3 амечания. Недостаточная сохранность не допускает точного определения. Ширина рабдосомы 0,7 мм; на 10 мм приходится примерно 6-8 тек.

12. Pristiograptus gregarius (Lapworth)

М а тери ал: скв. Oхесаaре, гл. 381,1 и 381,2 м; скв. Курси, гл. 24,6 $\mu$ (cf.); сг:в. Немси, гл. 34,8 м (сf.); скв. Ванаыуэ, гл. 43,3 м (ех: gr.); скв. Пыльтсамаа, гл. $32,1 \sim$ (ex. gr.).

3 а меч ания. Экземпляры из скв. Охесааре являются типичными представительми вида с длинной (5 мм) сикулой. У остальных теки расположены несколько более тесно $(11-12$ тек на 10 мм), чем обычно.

Кроме указанных 12 видов граптолитов, установленных с большей или меньшей достоверностью, в нижнем и среднем лландовери Эстонии встречается еще ряд представителей родов дендроидей (Dictyonema, Inocaulis, Estoniocaulis, Crinocaulis, Rhadinograptus; см. Обут, 1960) и сомнительных граптолитов (как Levéillites и др.). Дендроидеи наиболее характерны для райкК'олаского горизонта.

Распространение рассмотренных нами видов по разрезу показано на рисунке, где учтены их относительные расстояния от границ горизонтов; мощность горизонтов на рисунке показана как средняя всех изученных разрезов.

Распространение граптолитов на сводном разрезе показано менее точно, чем это можно сделать для каждого конкретного разреза, но зато это позволяет нагляднее выяснить общие закономерности распространения граптолитов в рассматриваемых горизонтах. Если теперь эти закономерности сравнить с известными нам данными о распространении тех же видов в других регионах [см. таблицу, которая составлена в основном по Elles \& Wood (1914) с использованием данных других авторов - Халецкой (1962), Bulman (1936), Waern (1948)], то можно сделать некоторые выводы о корреляции эстонского разреза с типовым разрезом Англин.

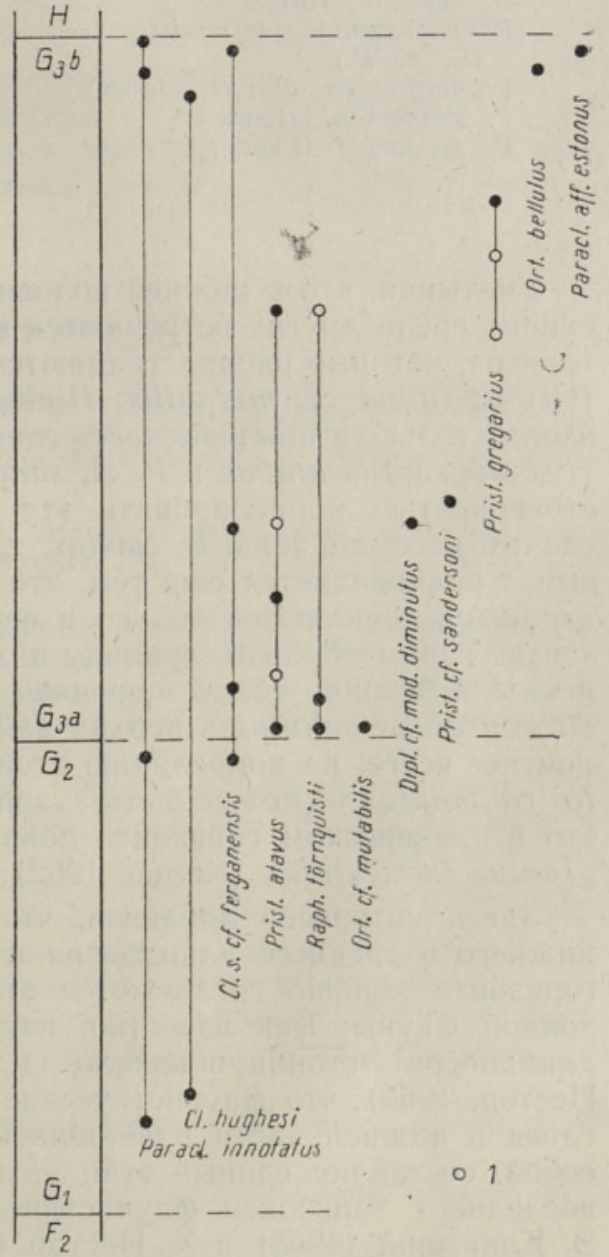

Распределение изученных граптолитов по разрезу:

1 - формы, определенные как conformis. 


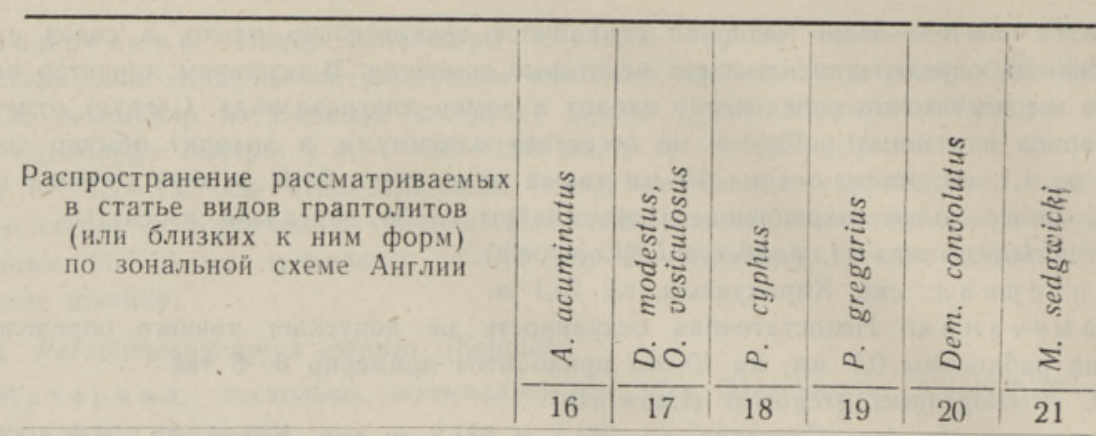

\footnotetext{
Climacograptus hughesi (Nich.)

Cl. scalaris ferganensis Obut

Paraclimacograptus innotatus

(Nich.)

Diplograptus modestus diminutus E. \& W.

Orthograptus mutabilis E. \&. W

$O$. bellulus Törnq.

Rhaphidograptus törnquisti (E. \& W.)

Pristiograptus atavus (Jones)

P. sandersoni (Lapw.)

P. gregarius (Lapw.)
}

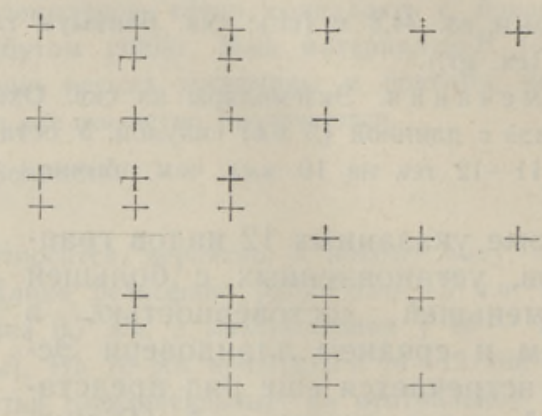

Учитывая, что в нижней половине райккюлаского горизонта (см. рисунок) среди других встречаются виды или близкие к ним формы граитолитов, которые распространяются не выше зоны Pristiograptus cyphus (Orthograptus cf. mutabilis, Diplograptus cf. modestus diminutus) или входят только в нижнюю часть следующей зоны Pristiograptus gregarius (Pristiograptus atavus и P. cf. sandersoni), то можно с достаточной достоверностью коррелировать эту часть райккюлаского горизонта со слоями не выше зоны $P$. cyphus, т. е. верхов нижнего лландовери. Этот вывод подкрепляется еще тем, что представители группы Pristiograptus gregarius появляются только в верхней половине райккюлаского горизонта. Таким образом, границу нижнего и среднего лландовери следует искать в Эстонии где-то в средней части названного горизонта. Находка Orthograptus bellulus в верхах райккюлаского горизонта указывает, вероятнее всего, на корреляцию этой части горизонта с зоной Demirastrites convolutus и, может быть, с зоной Monograptus sedgwicki, тем более что в адавереском горизонте появляются уже граптолиты зоны Spirograptus turriculatus (Кальо, 1962).

Здесь интересно добавить, что с выводом о проведении границы нижнего и среднего лландовери где-то в средней части райккюлаского горизонта хорошо согласуются этапы формирования некоторых групп донной фауны. Как известно, изучение строматопороидей и кораллов лландовери Эстонии показало (Клааманн, 1962; Нестор, 1964; Кальо, Нестор, 1966), что фаунистические комплексы юуруских и тамсалуских слоев и нижней части райккюлаского горнзонта тесно связаны между собой, составляя единый этап развития, тогда как в верхней половине последнего горизонта фаунистический комплекс сильно обновляется. Э. Клааманн (1965) и Х. Нестор (1964) выделяют здесь на этом основании даже особую зону - зону Parastriatopora celebrata или Clathrodictyon clivosum, отделяя ее от зоны Mesofavosites obliquus верхнего лландовери. Нам кажется, что отмеченную смену комплексов можно. 
считать маркирующей границу между нижним и средним лландовери в Эстонии.

Не менее интересны и комплексы брахиопод. Отметим здесь только, что, по заключению А. Буко (устное сообщение М. Рубеля), найденные в Эстонии из юуруских слоев представители Stricklandia lens наиболее сходны с номинальным подвидом или с формой prima. Учитывая, что в Англии эти стрикландии распространены в слоях $\mathrm{A}_{2}-\mathrm{A}_{4}$ нижнего лландовери (Williams, 1951) примерно на уровне зоны Diplograptus modestus и Orthograptus vesiculosus, мы имеем сравнительно ясное указание на возраст юуруских слоев.

Сказанное позволяет сделать вывод о том, что юуруские и тамсалуские слои вместе с нижней частью райккюлаского горизонта относятся по граптолитам несомненно к нижнему лландовери и соответственно раковинная фауна Эстонии с Clathrodictyon boreale Riab. и Ecclimadictyon microvesiculosum (Riab.), Palaeofavosites paulus Sok. и Mesofavosites fleximurinus Sok., Paliphyllum soshkinae Kaljo, Zygospiraella duboisi (Vern.), Pentamerus borealis Eichw. и др. является раннелландоверийской. Этот вывод не отрицает возможности распространения отдельных элементов названного комплекса в среднем лландовери.

Из сопоставления с типовым разрезом Англии мы также приходим к выводу, что если в Эстонии перерыв на границе ордовика и силура вообще существует, то он невелик и, вероятно, по своему объему соответствует не более чем самой нижней граптолитовой зоне силура.

\section{ЛИТЕРАТ У РА}

А алоэ А. О., 1958. Стратиграфия юуруского $\left(\mathrm{G}_{1}\right)$ и тамсалуского $\left(\mathrm{G}_{2}\right)$ горизонтов силура Эстонской ССР, Тр. Ин-та геол. АН ЭССР, 3.

Кальо Д. Л., 1962. О границе лландовери и венлока в Прибалтике, Тр. Ин-та геол. АН ЭССР, 10.

К альо Д. Л., Нестор Х. Э., 1966. Этапность формирования фауны строматопороидей и ругоз лландовери Эстонии, Тр. VIII сессии Всес. палеонт. об-ва. ВПО.

Қла ам анн Э. Р., 1962. Распространение ордовикских и силурийских табулят Эстонии (с описанием некоторых новых видов), Тр. Ин-та геол. АН ЭССР, 10.

Кла а м ан Э. Р., 1965. Биостратиграфическое расчленение ордовика и силура Прибалтики по табулятам, Сб. Табулятоморфные кораллы ордовика и силура CCCP, $M$.

Н естор Х. Э., 1964. Строматопорондеи ордовнка и лландовери Эстонии, Таллин.

Н ики форов а О. И., О у т А. М., 1965. Корреляция, Кн. Стратиграфия СССР. Силурийская система, M.

О 6 у т А. М., 1960. Корреляция некоторых частей разреза ордовикских и силурийских отложений Эстонской ССР по граптолитам, Тр. Ин-та геол. АН ЭССР, 5.

Халецкая О. Н., 1962. Граптолиты лландовери Западного Тянь-Шаня, Кн. Стратиграфия и палеонтология Узбекистана и сопредельных районов, Ташкент.

Bulman O. M. B., 1936. Rhaphidograptus, a new graptolite genus, Geol. Mag., 73.

Elles G. L., W ood E. M. R., 1914. Monograph of British Graptolites, pt. X, Palaeont. Soc. London.

K i a e r J., 1908. Das Obersilur in Kristianiagebiete, Vidensk. Selsk. Skrifter, 1. Math.Naturw. K1., 2.

M a rtna J., 1957. Notes on the Upper Ordovician and Lower Silurian of the Tapa district, Estonia. Geol. fören. Stockh. förhandl., 79.

Rosenstein E., 1940. Andmeid Juuru lademe kohta, Eesti Loodus, 8.

T eichert C., 1928. Stratigraphische und paläontologische Untersuchungen im unteren Gotlandium (Tamsalstufe) des westlichen Estland und der Insel Dagö. Neues Jahrb. Mineral., Geol. und Paläontol., Beilagebd, 60, Abt. B. 
Twenh of el W., 1916. The Silurian and high Ordovician strata of Estonia, Russia and their Faunas, Bull. Museum Compar. Zool. Harv. Coll., 56.

W a ern B., 1948. The Silurian Strata of the Kullatorp Core, Bull. Geol. Inst. Uppsala, 32 .

Williams A., 1951. Llandovery brachiopods from Wales with special reference to the Llandovery district, Quart. J. Geol. Soc. London, 107.
Институт геологии
Академии наує Эстонской ССР
Поступила в редакцию 25/V 1966

D. KALJO

\section{EESTI SILURI ALUMISTE LADEMETE VANUSEST}

Võrreldes juuru $\left(\mathrm{G}_{1}\right)$ ja tamsalu $\left(\mathrm{G}_{2}\right)$ kihtidest ning raikküla lademest $\left(\mathrm{G}_{3}\right)$ leitud graptoliitide levikut (joon.) nende seni teadaoleva levikuga (tabel), jōutakse järeldusele, et keskländouverisse kuulub ainult raikküla lademe ülemine pool $\left(\mathrm{G}_{3} \mathrm{~b}\right)$; lademe alumine pool $\left(\mathrm{G}_{3} \mathrm{a}\right)$ vastab alamländouveri ülemisele osale, $\mathrm{G}_{1-2}$ aga ilmselt veel madalamatele kihtidele. Kui siluri alumises osas üldse esineb lünka, siis on viimane küllaltki piiratud.

Juhitakse tähelepanu sellele, et stromatopooride ja korallide kompleks on ühtne $\mathrm{G}_{1-2}-\mathrm{G}_{3}$ a piires; $\mathrm{G}_{3} \mathrm{~b}$ kompleks seevastu erineb nii eelmisest kui ka järgmisest adavere lademele $(\mathrm{H})$ iseloomulikust ülemländouveri kompleksist. Selline etapilisus fauna formeerumises vastab ländouveri liigestusele alamladejărkudeks.

\section{KALJO}

\section{ON THE AGE OF THE LOWERMOST SILURIAN OF ESTONIA}

On the basis of correlations, J. Kiaer (1908), C. Teichert (1928) and some other authors were of the opinion that the lowermost Silurian is missing in Estonia. Namely, the Juuru $\left(\mathrm{G}_{1}\right)$, Tamsalu $\left(\mathrm{G}_{2}\right)$ and Raikküla strata $\left(\mathrm{G}_{3}\right)$ of Estonia were correlated either to the Middle Llandovery, or to the uppermost Lower and the Middle Llandovery. Only J. Martna (1957) and A.. Aaloe (Аалоэ, 1958) stated that there does not exist any considerable hiatus on the border of the Ordovician and Silurian in Estonia.

The distribution of the graptolites found in the above-mentioned strata (fig.) indicates that only the upper part of the Raikküla stage $\left(\mathrm{G}_{3} \mathrm{~b}\right)$ corresponds to the Middle Llandovery; its lower part $\left(\mathrm{G}_{3} \mathrm{a}\right)$ certainly corresponds to the upper part of the Lower Llandovery, $G_{1-2}$ obviously being even older. If there exists a hiatus in the lowermost Silurian of Estonia at all, it is at any rate rather limited.

Attention is drawn to the fact that the assemblage of stromatopores and corals in uniform within the limits of $\mathrm{G}_{1-2}+\mathrm{G}_{3}$ a (the so-called Clathrodictyon boreale Riab., Palaeofavosites paulus Sok., Paliphyllum soshkinae Kaljo and Pentamerus borealis Eichw. assemblage); on the other hand, the assemblage of $\mathrm{G}_{3} \mathrm{~b}$ (Clathrodictyon clivosum Nestor, Parastriatopora celebrata Klaam., etc.) differs from both the abovementioned and the succeeding assemblage of the Upper-Llandoverian Adavere stage (H). These assemblages are in good accordance with the classification of Llandoverian rocks into three subseries. 